\title{
The effect of use different concentrations of sodium hypochlorite on cyclic fatigue in reciproc files (in vitro study)
}

\author{
Alaa Muhamad ${ }^{*}$, Hisham Alafif ${ }^{2}$ \\ ${ }^{1} \mathrm{MSc},{ }^{2}$ Professor, Dept. of Endodontics and Restorative Dentistry, Damascus University, Syria
}

*Corresponding Author: Alaa Muhamad

Email: alaa3m89@gmail.com

\begin{abstract}
Background: NiTi instruments have a risk of separation due to torsional or flexural fatigue (cyclic fatigue). Chemo-mechanical preparation and cleaning procedures cause the corrosion of endodontic instruments that may weaken the fracture resistance of the instruments.

Aim of the Study: To assess resistance to cyclic fatigue of Reciproc files R25 after immersion in different concentrations of sodium hypochlorite in conditions similar to those used in clinical practice.

Materials and Methods: The study sample included 40 new Reciproc R25 files according to the G-power program and divided randomly into four groups according to $\mathrm{NaOCl}$ concentration $(\mathrm{n}=10)$. Files were immersed in $\mathrm{NaOCl}$ for 10 minutes at room temperature and for $16 \mathrm{~mm}$ length as following: Group A no immersion (control), Group B (1\% NaOCl), Group C (2.5\% NaOCl) and $\mathrm{Group} \mathrm{D} \mathrm{(5.25 \%} \mathrm{NaOCl).} \mathrm{The}$ cyclic fatigue resistance was tested in stainless steel artificial canal manufactured reproducing the instrument size and taper, with $120^{\circ}$ angle of curvature and 2.5 radius of curvature. The Time to Fracture (TtF) was statically analyzed.

Results: According to statistical data for analytical study, the mean of Time to Fracture (TtF) group A control, B, C and D was170.77,153.10,142.32, and 132.59 respectively. One-way ANOVA test indicated no significant differences in mean of TtF between $\mathrm{NaOCl}$ concentration groups. Resistance to cyclic fatigue of $\mathrm{R} 25$ was not affected by the concentration of $\mathrm{NaOCl}$ used in this study ( $\mathrm{P}>0.05)$. Conclusions: Using different concentrations of $\mathrm{NaOCl}$ for 10 minutes did not reduce the resistance to cyclic fatigue of Reciproc $\mathrm{R} 25$ files.
\end{abstract}

Keywords: Cyclic fatigue, $\mathrm{NaOCl}$, Reciproc R25.

\section{Introduction}

The success of Endodontic treatment is related to the cleaning and shaping of the root system, which is controlled by mechanical factors such as the preparation method and the preparation system followed by chemical agents containing irrigation solutions and their effectiveness in tissue solution, germination and removal of residues. ${ }^{1}$

NiTi files are used to achieve cleaning and shaping objectives in the context of endodontic treatment, and have many features that make them superior to stainless steel files such as high flexibility, cutting ability and speed. ${ }^{2}$ Although widely spread, they have a high risk of fracture due to cyclic fatigue after prolonged clinical use. ${ }^{3-5}$

The fracture caused by cyclic fatigue occurs unexpectedly without any prior signs of malfunctions, ${ }^{6}$ due to the instrument exposure to repeated cycles of tensile and pressure stresses in the maximum curvature area when the instrument rotates in the curved canal. ${ }^{7}$ Whereas the fracture is caused by torsional fatigue when the head of the instrument or any other part of it stuck inside the canal while the instrument's neck continues rotating. ${ }^{8}$

Corrosion is an important factor in weakening the resistance of the alloy. It is caused in endodontic instruments by cleaning, disinfection and sterilization procedures. ${ }^{9}$ $\mathrm{NaOCl}$ is the most common irrigants in the endodontic treatment due to its antibacterial and tissue solution properties. ${ }^{10}$ However, active clo $^{-}$increases the chance of corrosion where it selectively removes the nickel from the surface of metal, causing microscopic fissures that concentrate the stresses and increase the chance of fracture. ${ }^{11}$
NiTi file resistance can be developed by improving manufacturing procedures and using new alloys with higher mechanical properties. ${ }^{12}$ The M-wire alloy was introduced in the market by DENTSPLY in 2007 and the manufacturer stated that it subjected to a series of heat treatments and hardening cycles during manufacturing, ${ }^{13}$ which gave it a set of features that made it superior to traditional NiTi files such as high flexibility, ${ }^{14}$ fracture resistance, ${ }^{15}$ and longer life span. ${ }^{16}$

In 2008, Yared introduced the reciprocation motion system using a single F2 Protaper instrument. ${ }^{2}$ After that it was followed by the introduction of two types of single-file reciprocating systems that rely on the M-wire alloy in the manufacture of its files. ${ }^{17}$ This file was designed with specific angles of the cutting blades that allow it to cut counterclockwise to be inserted into the dentine while the rotation with the clock allows the tool to be disengaged. Thus, the result is the advancement of the instrument in the root canal. $^{18}$

The Reciproc (VDW GmbH, Munich Germany) was introduced as a single-file reciprocation motion system, made of NiTi M-wire alloy, giving higher flexibility properties of $300 \%-800 \%$ and greater resistance to cyclic fatigue than traditional NiTi. ${ }^{19}$

There are many studies on cyclic fatigue resistance using different NiTi files with different designs and compositions. ${ }^{7,20}$, There are also studies on the effect of sodium hypochlorite solution on cyclic fatigue resistance in NiTi files and in M-wire files. ${ }^{21-24}$ However, no studies are available on the effect of sodium hypochlorite concentration on cyclic fatigue in M-wire files. 


\section{The Aim of the Study}

To assess the effect of different concentrations of $\mathrm{NaOCl} 1 \%$, $2.5 \%, 5.25 \%$ on cyclic fatigue in Reciproc files (manufactured from M-wire and works in reciprocating motion) under conditions similar to those used in clinical practice.

\section{Materials and Methods}

A total of 40 new Reciproc R25 instruments, which had an ISO size 25 at the tip, a taper of 0.08 in the apical $3 \mathrm{~mm}$ and a length of $25 \mathrm{~mm}$ were selected. Each instrument was inspected for defects or deformities before the experiment and none was discarded. Files were randomly divided into four different groups of 10 each. Group A (control) was composed of new instruments not immersed in solution. Instruments of groups $\mathrm{B}, \mathrm{C}$ and $\mathrm{D}$ were immersed in $1 \%$, $2.5 \%$ and $5.25 \%$ of $\mathrm{NaOCl}$ respectively for 16 millimeter at room temperature and for $10 \mathrm{~min}$. immediately after removal from the solutions, all files were rinsed in distilled water to neutralize the effect of $\mathrm{NaOCl}$ and dried.

Instruments of all four groups were then subjected to cyclic fatigue testing using a mechanical device specifically developed for the purpose that allowed a reproducible simulation of an instrument confined in a curved canal. ${ }^{25,26}$ (Fig 1)

The device contained a block of stainless steel with three artificial canals corresponding the instrument's size and taper. For this study, it was selected the canal with a $120^{\circ}$ angle of curvature and $5 \mathrm{~mm}$ radius of curvature measured according to the method of Schneider. ${ }^{27}$ The end of the curvature was $6 \mathrm{~mm}$ from the tip of the instrument. A glass top face cover allowed visualization of the files rotating in the canal and the removal of broken instruments between tests.

To reduce the friction of the file when contacting with the artificial canal walls, special high-flow synthetic oil designed for lubrication (Super Oil; Singer Co Ltd, Elizabeth port NJ, USA) was sprayed into the simulated canal.

The device was connected to a 6:1 handpiece (Sirona Dental Systems GmbH, Bensheim, Germany), powered by VDW.SILVER ${ }^{\circledR}$ RECIPROC $^{\circledR}$ motor (VDW) with recommended setting for Reciproc files with the 'RECIPROC ALL' mode.

After positioning the instrument in the canal and as soon as rotation started, a video camera (Konica minolta lens - $\mathrm{f}=2.2 \sim 85.8 \mathrm{~mm}$ 1:1.8) was recorded the movement. The recording was stopped when instrument breakage was achieved. The video files were transferred to the computer to be processed by Camtasia 9 with slow monitoring for each instrument to calculate and register the time to fracture $(\mathrm{TtF})$ in seconds from the start of the test until the moment of breakage.

One-way ANOVA analysis was used to evaluate the effect of immersion in hypochlorite solution on cyclic fatigue resistance.

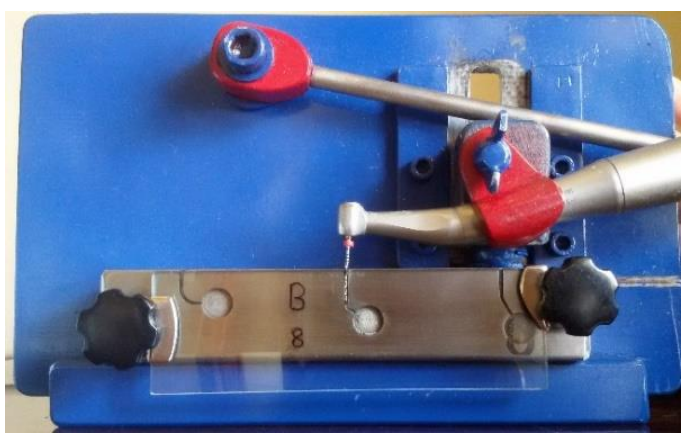

Fig. 1

\section{Results}

Descriptive statistics of $\mathrm{TtF}$ for the each file are summarized in Table 1.

The mean of Time to Fracture was inversely proportional to $\mathrm{NaOCl}$ concentration (Graph1) with no statistical significance (One-Way ANOVA, $\mathrm{P}=0.057$ ). Also, there were no significant differences in regarding to mean $\mathrm{TtF}$ between the $\mathrm{NaOCl}$ concentration groups (control, $1 \%, 2.5 \%$, and $5.25 \%$ ) Table 2.

Graph 1: Mean of time to fracture according to $\mathrm{NaOCl}$ Concentration group

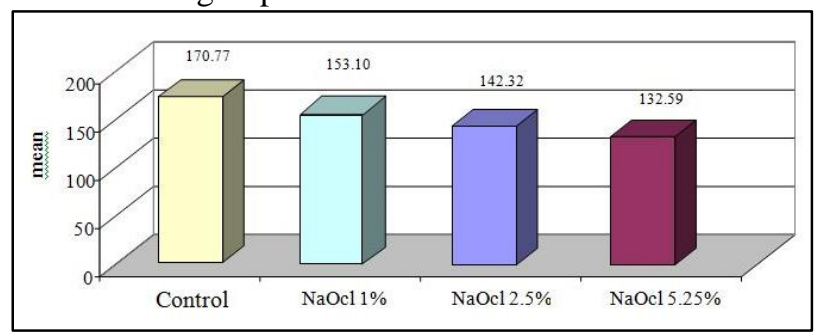

Table 1: Descriptive statistics of cyclic fatigue resistance: $\mathrm{TtF}$ for instruments in seconds

\begin{tabular}{|l|c|c|c|c|c|c|c|}
\hline Concentration of NaOCl & Group & $\mathbf{N}$ & Mean (s) & Standard deviation & Standard error of mean & Min & Max \\
\hline control & $\mathrm{A}$ & 10 & 170.77 & 27.54 & 9.74 & 120.33 & 194.90 \\
\hline $1 \%$ & $\mathrm{~B}$ & 10 & 153.10 & 15.35 & 5.43 & 126.6 & 180.46 \\
\hline $2.5 \%$ & $\mathrm{C}$ & 10 & 142.32 & 16.80 & 5.94 & 118.5 & 169.84 \\
\hline $5.25 \%$ & $\mathrm{D}$ & 10 & 132.59 & 41.86 & 14.80 & 56.7 & 172.5 \\
\hline
\end{tabular}

*TtF: Time to Fracture

Table 2: One Way ANOVA analysis results.

\begin{tabular}{|l|c|c|c|}
\hline The studied variable & F value & Significance level value & Indication of differences \\
\hline $\begin{array}{l}\text { Time to Fracture } \\
\text { (in seconds) }\end{array}$ & 2.826 & 0.057 & There are no significant differences \\
\hline
\end{tabular}

$* \mathrm{P}>0.05$ 


\section{Discussion}

The cyclic fatigue effects on NiTi's fracture is still controversial in the medical literature and despite its high flexibility and high resistance, refraction is the main problem in NiTi files, especially during prolonged clinical use. ${ }^{28,29}$ Where instruments are exposed to a range of factors that control their life spam, such as instrument design and cross section, ${ }^{30}$ radius and angle of curvature, ${ }^{31}$ speed, torque and motion system, ${ }^{32}$ sterilization, disinfection and irrigation procedures. ${ }^{9}, 33$

Several strategies have been suggested to improve the cyclic fatigue resistance of traditional NiTi files, including improving the $\mathrm{NiTi}$ alloy by heat processing during manufacturing to give a higher elasticity and higher resistance than $\mathrm{M}$-wire. ${ }^{19}$ The reciprocation motion system has also been suggested to increase safety with regard to instruments reaction, as the pattern of reciprocation motion and counterclockwise reduces the probability of fracture by decreasing the pressure forces leading to cyclic fatigue, ${ }^{34}$ and reducing bending stresses caused by the disintegration of the instruments. ${ }^{35}$

Reciproc system was selected for this study as a single file reciprocating system, made of M-wire. ${ }^{17,20}$ It was proved its superiority on a number of systems in terms of pattern of motion and reciprocating motion increased its resistance to cyclic fatigue compared to the rotational motion. ${ }^{18}$ In addition, the single file system reduces $60 \%$ of the work time compared to multiple files systems. ${ }^{36} \mathrm{As}$ it is made of M-wire alloy which improves the instruments' resistance to fracture compared to the traditional NiTi alloy. ${ }^{19}$

Reciproc approved its superiority to WAVE ONE in terms of resistance to cyclic fatigue after contact with $\mathrm{NaOCl} .{ }^{20}$ As the sodium hypochlorite $\mathrm{NaOCl}$ considered the most common irrigation agent in endodontic treatment because of its antibacterial and tissue solution properties. ${ }^{10}$ Therefore, the potential adverse effect of hypochlorite contact with the NiTi M-wire was studied.

To approach clinical reality, The Reciproc R25 was immersed in different concentrations of sodium hypochlorite solutions used clinically, for 10 minutes at room temperature to stay within the realistic limits of the time required to prepare a canal using a single file, and $16 \mathrm{~mm}$ of file length was immersed which is the part of the file contacting hypochlorite during root canal preparation.

Then the files were tested in the cyclic fatigue meter device containing artificial canals matching the size and taper of the $\mathrm{R} 25$ files $(+0.1 \mathrm{~mm})$ to ensure a repeatable path in terms of curvature radius and angle. Where using a non-matching canals to the studied file dimensions leads to a large variation in studies' results. ${ }^{26}$

The rotation speed of the reciprocal motion cannot be determined precisely because of the electric motor limitation in direction alteration adjustment. ${ }^{37}$ Therefore, time to Fracture $\mathrm{TtF}$ was determined in addition tothe number of cycles to fracture NCF.

Under the conditions of this study, the Reciproc R25 immersion in the sodium hypochlorite solution for 10 minutes did not decrease its resistance to cyclic fatigue regardless the concentration used clinically.

The studies of cyclic fatigue resistance reported conflicting results in regarding of NiTi files and M-wire files after contact with sodium hypochlorite solution. Where the results of this study agreed with the study of Pedulla, which stated that the immersion of R25 files in sodium hypochlorite solution for 1 or 5 seconds did not reduce their resistance to cyclic fatigue. ${ }^{23}$ This also applied to traditional NiTi (Revo S, M-two, and TF) files when immersed in sodium hypochlorite solution. ${ }^{21}$ The researchers attributed this to the location of corrosion in the file. Accordingly, if the corrosion is not in the concentration efforts area, cyclic fatigue will not be affected. This was confirmed by Bulem when he pointed out that the cyclic fatigue resistance will often not be affected negatively with active immersion of NiTi files in sodium hypochlorite solution or with autoclave sterilization. ${ }^{38}$ The results of this study did not disagreed with Elnaghy study, which confirmed that the immersion of Reciproc and WaveOne Gold in sodium hypochlorite reduced significantly their resistance to cyclic fatigue..$^{39}$ The resistance of R25 was also affected with sodium hypochlorite by adding surfactants according to Padilla study. ${ }^{40}$ In traditional NiTi files, Peters indicated that cyclic fatigue resistance decreased significantly after $\mathrm{NaOCl}$ immersion for 2 hours at $60^{\circ} \mathrm{c},{ }^{22}$ this may attribute to long immersion time and high temperature. Berutti also confirmed that immersion of the entire Protaper $\mathrm{F} 2$ in a $5 \% \mathrm{NaOCl}$ solution for 5 minute would affect more than the $16 \mathrm{~mm}$ immersion of the file. ${ }^{24}$ This is not achieved clinically as the file shank is not in contact with hypochlorite during canal preparation. Within the limits of this research we can conclude that the immersion of Reciproc R25 files in sodium hypochlorite in clinical practice don't affect its resistance to cyclic fatigue.

\section{Source of Funding}

None.

\section{Conflict of Interest}

None.

\section{References}

1. Estrela CR, Estrela C, Reis C, Bammann LL, Pecora JD. Control of microorganisms in vitro by endodontic irrigants. Braz Dent J. 2003;14(3):187-92.

2. Yared G. Canal preparation using only one Ni-Ti rotary instrument: preliminary observations. Int Endod J. 2008;41(4):339-44

3. You SY, Bae KS, Baek SH, Kum KY, Shon WJ, Lee W. Lifespan of one nickel-titanium rotary file with reciprocating motion in curved root canals. J Endod. 2010;36(12):1991-4.

4. Alapati SB, Brantley WA, Svec TA, Powers JM, Mitchell JC. Scanning electron microscope observations of new and used nickel-titanium rotary files. J Endod. 2003;29(10):667-9.

5. Shen Y, Qian W, Abtin H, Gao Y, Haapasalo M. Fatigue testing of controlled memory wire nickel-titanium rotary instruments. J Endod. 2011;37(7):997-1001.

6. Wei X, Ling J, Jiang J, Huang X, Liu L. Modes of failure of ProTaper nickel-titanium rotary instruments after clinical use J Endod. 2007;33(3):276-9. 
7. Gambarini G. Cyclic fatigue of nickel-titanium rotary instruments after clinical use with low- and high-torque endodontic motors. J Endod. 2001;27(12):772-4.

8. Martin B, Zelada G, Varela P, Bahillo JG, Magan F, Ahn S, et al. Factors influencing the fracture of nickel-titanium rotary instruments. Int Endod J. 2003;36(4):262-6.

9. O'Hoy PY, Messer HH, Palamara JE. The effect of cleaning procedures on fracture properties and corrosion of NiTi files. Int Endod J. 2003;36(11):724-32.

10. Arruda MP, Carvalho Junior JR, Miranda CE, Paschoalato C, Silva SR. Cleaning of flattened root canals with different irrigating solutions and nickel-titanium rotary instrumentation. Braz Dent J. 2009;20(4):284-9.

11. Sarkar NK, Redmond W, Schwaninger B, Goldberg AJ. The chloride corrosion behaviour of four orthodontic wires. J Oral Rehabil. 1983;10(2):121-8.

12. Larsen CM, Watanabe I, Glickman GN, He J. Cyclic fatigue analysis of a new generation of nickel titanium rotary instruments. J Endod. 2009;35(3):401-3.

13. Kell T, Azarpazhooh A, Peters OA, El-Mowafy O, Tompson B, Basrani B. Torsional profiles of new and used 20/.06 GT series X and GT rotary endodontic instruments. $J$ Endod. 2009;35(9):1278-81.

14. Hieawy A, Haapasalo M, Zhou H, Wang ZJ, Shen Y. Phase Transformation Behavior and Resistance to Bending and Cyclic Fatigue of ProTaper Gold and ProTaper Universal Instruments. J Endod. 2015;41(7):1134-8.

15. Gambarini G, Gerosa R, De Luca M, Garala M, Testarelli L. Mechanical properties of a new and improved nickel-titanium alloy for endodontic use: an evaluation of file flexibility. Oral Surg, Oral Med, Oral Pathol, Oral Radiol, Endod. 2008;105(6):798-800

16. Gao Y, Shotton V, Wilkinson K, Phillips G, Johnson WB. Effects of raw material and rotational speed on the cyclic fatigue of ProFile Vortex rotary instruments. J Endod. 2010;36(7):1205-9.

17. Yared G, Alasmar Ramli G. Single file reciprocation: A literature review. Endod Pract Today. 2013;7(3).

18. Gavini G, Caldeira CL, Akisue E, Candeiro GT, Kawakami DA. Resistance to flexural fatigue of Reciproc R25 files under continuous rotation and reciprocating movement. $J$ Endod. 2012;38(5):684-687.

19. Shen Y, Zhou HM, Zheng YF, Peng B, Haapasalo M. Current challenges and concepts of the thermomechanical treatment of nickel-titanium instruments. J Endod. 2013;39(2):163-72.

20. Plotino G, Grande NM, Testarelli L, Gambarini G. Cyclic fatigue of Reciproc and Wave One reciprocating instruments. Int Endod J. 2012;45(7):614-8.

21. Pedulla E, Grande NM, Plotino G, Pappalardo A, Rapisarda E. Cyclic fatigue resistance of three different nickel-titanium instruments after immersion in sodium hypochlorite. J Endod. 2011;37(8):1139-42.

22. Peters OA, Roehlike JO, Baumann MA. Effect of immersion in sodium hypochlorite on torque and fatigue resistance of nickeltitanium instruments. $J$ Endod. 2007;33(5):589-93.

23. Pedulla E, Grande NM, Plotino G, Palermo F, Gambarini G, Rapisarda E. Cyclic fatigue resistance of two reciprocating nickel-titanium instruments after immersion in sodium hypochlorite. Int Endod J. 2013;46(2):155-9.

24. Berutti E, Angelini E, Rigolone M, Migliaretti G, Pasqualini D. Influence of sodium hypochlorite on fracture properties and corrosion of ProTaper Rotary instruments. Int Endod J. 2006;39(9):693-9.

25. Grande NM, Plotino G, Pecci R, Bedini R, Malagnino VA, Somma F. Cyclic fatigue resistance and three-dimensional analysis of instruments from two nickel-titanium rotary systems. Int Endod J. 2006;39(10):755-63.
26. Plotino G, Grande NM, Cordaro M, Testarelli L, Gambarini G. Measurement of the trajectory of different NiTi rotary instruments in an artificial canal specifically designed for cyclic fatigue tests. Oral Surg, Oral Med, Oral Pathol, Oral Radiol, Endod. 2009;108(3):e152-6.

27. Schneider SW. A comparison of canal preparations in straight and curved root canals. Oral Surg, Oral Med, Oral Pathol. 1971;32(2):271-5.

28. Wu J, Lei G, Yan M, Yu Y, Yu J, Zhang G. Instrument separation analysis of multi-used ProTaper Universal rotary system during root canal therapy. J Endod. 2011;37(6):758-63.

29. Parashos P, Messer HH. Rotary NiTi instrument fracture and its consequences. $J$ Endod. 2006;32(11):1031-43.

30. Turpin YL, Chagneau F, Vulcain JM. Impact of two theoretical cross-sections on torsional and bending stresses of nickeltitanium root canal instrument models. $J$ Endod. 2000;26(7):414-7.

31. Pruett JP, Clement DJ, Carnes DL. Cyclic fatigue testing of nickel-titanium endodontic instruments. $J$ Endod. 1997;23(2):77-85.

32. Peters OA, Paque F. Current developments in rotary root canal instrument technology and clinical use: a review. Quintessence Int. 2010;41(6):479-88.

33. Chaves Craveiro de Melo M, Guiomar de Azevedo Bahia M, Lopes Buono VT. Fatigue resistance of engine-driven rotary nickel-titanium endodontic instruments. $J$ Endod. 2002;28(11):765-9.

34. De-Deus G, Moreira EJ, Lopes HP, Elias CN. Extended cyclic fatigue life of F2 ProTaper instruments used in reciprocating movement. Int Endod J. 2010;43(12):1063-8.

35. Varela-Patino P, Ibanez-Parraga A, Rivas-Mundina B, Cantatore G, Otero XL, Martin-Biedma B. Alternating versus continuous rotation: a comparative study of the effect on instrument life. J Endod. 2010;36(1):157-9.

36. Bürklein S, Hinschitza K, Dammaschke T, Schäfer E. Shaping ability and cleaning effectiveness of two single-file systems in severely curved root canals of extracted teeth: Reciproc and WaveOne versus Mtwo and ProTaper. Int Endod J. 2012;45(5):449-61.

37. Kim HC, Kwak SW, Cheung GSP, Ko DH, Chung SM, Lee W. Cyclic fatigue and torsional resistance of two new nickeltitanium instruments used in reciprocation motion: Reciproc versus WaveOne. J Endod. 2012;38(4):541-4.

38. Bulem UK, Kececi AD, Guldas HE. Experimental evaluation of cyclic fatigue resistance of four different nickel-titanium instruments after immersion in sodium hypochlorite and/or sterilization. J Appl Oral Sci: Rev FOB. 2013;21(6):505-10.

39. Elnaghy AM, Elsaka SE. Effect of sodium hypochlorite and saline on cyclic fatigue resistance of WaveOne Gold and Reciproc reciprocating instruments. Int Endod J. 2017;50(10):991-8.

40. Pedulla E, Franciosi G, Ounsi HF, Tricarico M, Rapisarda E, Grandini S. Cyclic fatigue resistance of nickel-titanium instruments after immersionin irrigant solutions with or withour surfactants. J Endod. 2014;40(8):1245-9.

How to cite this article: Muhamad A, Alafif $\mathrm{H}$. The effect of use different concentrations of sodium hypochlorite on cyclic fatigue in reciproc files (in vitro study). Int J Oral Health Dent 2020;6(1):8-11. 